\title{
Persistent Pain after Clay Shoveler's Fracture Delayed Union: The Role for Ultrasound-Guided Corticosteroid Injection
}

\author{
Ike B. Hasley, MD ${ }^{1^{*}}$, Marc P. Gruner, DO ${ }^{1,2}$, David B. Soma, $M D^{2,3}$ and Jacob L. Sellon, $M D^{1,2}$ \\ ${ }^{1}$ Department of Physical Medicine and Rehabilitation, USA \\ ${ }^{2}$ Division of Sports Medicine, Department of Orthopedic Surgery, USA \\ ${ }^{3}$ Department of Pediatric and Adolescent Medicine, USA

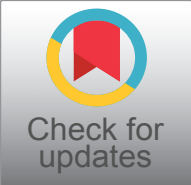

*Corresponding author: Ike Hasley, M.D, Department of Physical Medicine and Rehabilitation, Mayo Clinic, 200 First Street SW, Rochester, MN, 55905, USA, Tel: 507-266-8913, Fax: 507-284-3431

\begin{abstract}
Clay shoveler's fracture is an avulsion fracture of the lower cervical or upper thoracic spinous processes. This injury can be seen in trauma and sports-related activity, and usually responds to rest from painful activity. Patients with persistent pain may be treated with surgical excision of the avulsion fragment. We describe the case of a 14 year-old competitive swimmer whose desire to return to sport after failed initial treatment led to pursuit of an ultrasound-guided anesthetic/corticosteroid injection of the avulsion fracture interval. This led to rapid symptom relief and return to sport. Such an injection may be useful for diagnostic and potentially therapeutic purposes prior to surgical excision in the cases of delayed union or non-union clay shoveler's fractures.
\end{abstract}

\section{Keywords}

Clay shoveler's fracture, Ultrasound-guided injection

\section{Introduction}

Clay shoveler's fracture is a relatively rare spinous process avulsion fracture that can be seen in trauma and sports-related activities [1-3]. Treatment is typically conservative [2]. In cases where neck pain persists, options are limited, but surgical excision can be considered. We present a case of an adolescent athlete in which initial treatment failed, leading to pursuit of a diagnostic and therapeutic ultrasound-guided injection. This ultimately led to a relatively rapid return to competitive sport. To our knowledge, this is the first case of an ultrasound-guided injection being used to treat this condition. This report illustrates a treatment option to consider after initial treatment has failed in order to avoid surgical intervention and prolonged delay from return to sport.

\section{Case Description}

A 14 year-old otherwise healthy male competitive swimmer was referred to Sports Medicine clinic after five weeks of upper back pain that started suddenly while lunging forward to kick a soccer ball. There was no direct blow or trauma. The patient was in the midst of a competitive swim season, and noted increased pain with attempts to return to swimming activities. His pain was described as sharp and rated at up to eight out of 10 in intensity. He denied radiculopathy symptoms. Initial exam was notable for tenderness to palpation over the T1 spinous process. Neurological exam and cervical range of motion were normal, with minor pain in extreme flexion. Initial radiographs demonstrated a small, well-corticated osseous fragment along the postero inferior aspect of the $\mathrm{T} 1$ spinous process, consistent with a minimally displaced spinous process fracture (Figure 1). The decision was made to treat conservatively with pain-limited rest and physical therapy. At follow-up eight weeks post-injury, the patient noted only minimal improvement.

Due to the patient's persistent symptoms, lack of improvement with rest and attempted return to activity, and evidence of delayed union on plain films, con-

Citation: Hasley IB, Gruner MP, Soma DB, Sellon JL (2021) Persistent Pain after Clay Shoveler's Fracture Delayed Union: The Role for Ultrasound-Guided Corticosteroid Injection. Int J Sports Exerc Med 7:189. doi.org/10.23937/2469-5718/1510189

Accepted: April 12, 2021; Published: April 15, 2021

Copyright: (C) 2021 Hasley IB, et al. This is an open-access article distributed under the terms of the Creative Commons Attribution License, which permits unrestricted use, distribution, and reproduction in any medium, provided the original author and source are credited. 


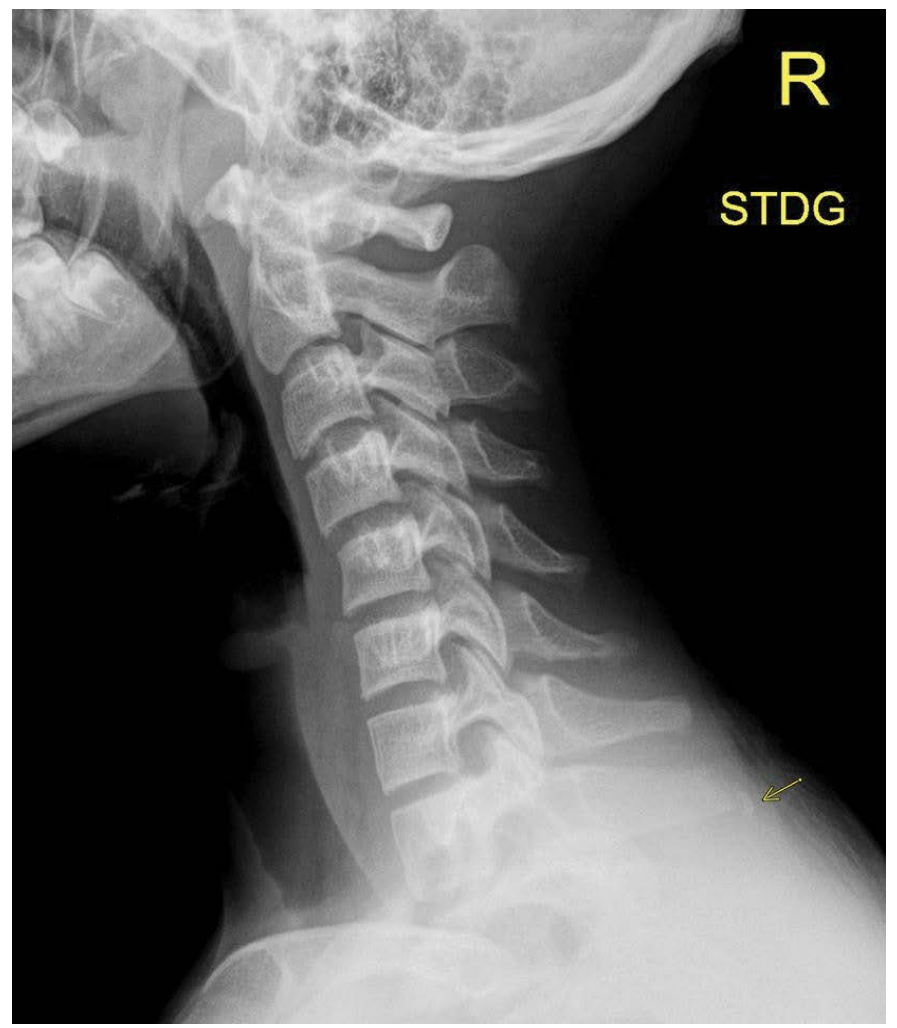

Figure 1: Lateral radiographs of the cervical spine demonstrating a small, well-corticated osseous fragment along the posteroinferior aspect of the T1 spinous process, consistent with a minimally displaced spinous process fracture.

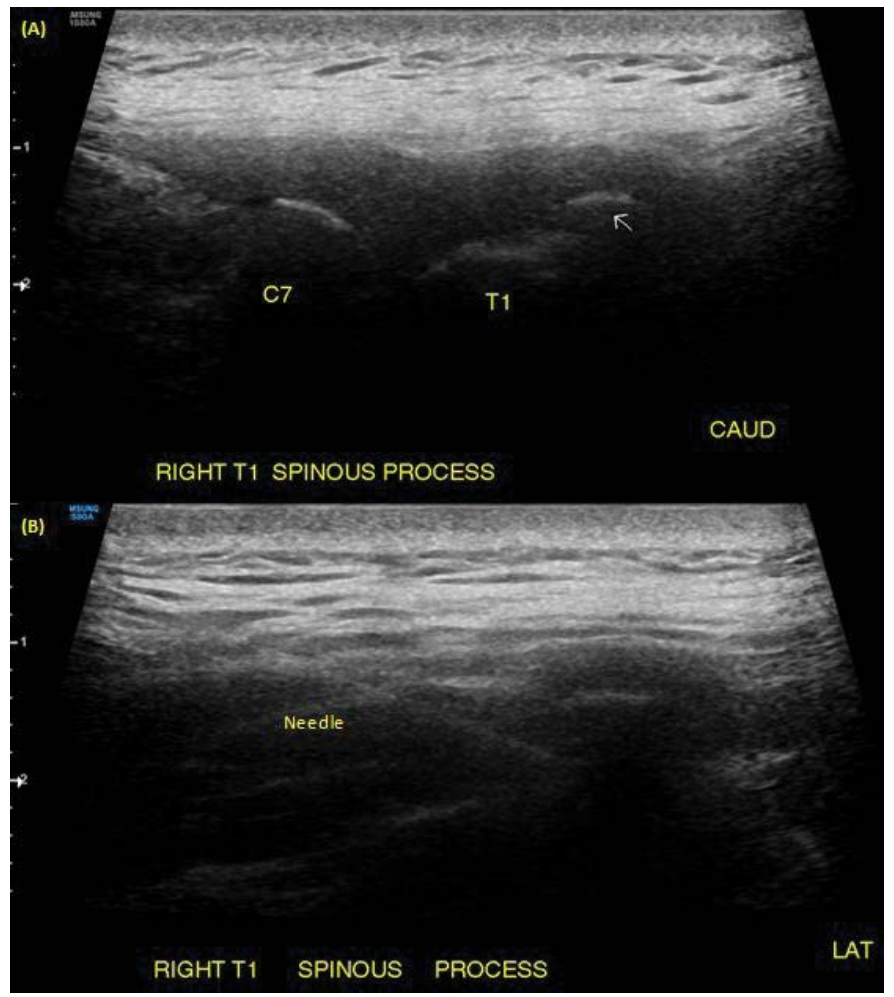

Figure 2: Ultrasound images $(A)$ parasagittal view just right of midline, showing T1 spinous process fracture (white arrow); (B) axial view at the level of the fracture, showing needle from left delivering anesthetic/corticosteroid injection into fracture interval.

sideration was given to more invasive treatment options. Surgical excision was considered, but due to the patient's strong desire to return to his competitive swim season, he and his family decided that he would trial an anesthetic/corticosteroid injection for diagnostic and potentially therapeutic purposes. After a discussion of risks/benefits, the patient underwent ultrasound-guided anesthetic/corticosteroid injection into the T1 spi- 
nous process fracture (Figure 2). This was performed with the patient in a prone position with arms at his side. A pre-procedure ultrasound scan localized the patient's maximal tenderness to the T1 level with evidence of a displaced fragment off the right side of the T1 spinous process. A 25 gauge, 2 inch needle was advanced from a lateral to medial approach under direct sonographic guidance into the T1 spinous process avulsion fracture interval. A $1 \mathrm{~mL}$ mixture of $2 \mathrm{mg} / 0.5 \mathrm{~mL}$ dexamethesone and $0.5 \mathrm{~mL}$ of $0.5 \%$ ropivacaine was injected with good sonographic flow. There were no complications. The patient noted some initial relief of his neck pain within a few minutes after the procedure. He was instructed to ice the area for pain control, avoid submersion to reduce risk of injection, and avoid vigorous activities for the rest of the day.

At two-week follow up post-procedure, the patient demonstrated complete resolution of pain and symptoms. His physical therapy was progressed, and he was able to successfully return to swimming. At one-year follow-up, the patient reported complete and sustained resolution of symptoms. He had successfully returned to compete in the latter half of his soccer season, and was participating fully in his swimming season until it was cancelled due to the COVID pandemic.

\section{Conclusion}

Clay shoveler's fracture is a rare avulsion fracture of the lower cervical or upper thoracic spinous processes, most commonly at C7 or T1 [1]. This was historically an occupational injury seen in the early $20^{\text {th }}$ century as a result of manual laborers, such as clay shovelers, lifting and throwing heavy objects, hence its name $[1,2]$. However, this is now more commonly seen in acute traumatic cases, such as motor vehicle accidents, as well as in athletes exerting sudden or rotational forces $[1,2]$. The pathophysiologic mechanism of this injury is thought to be secondary to shearing forces exerted by forceful contraction of the upper back and neck muscles that attach to the spinous processes, notably the trapezius and rhomboid muscles [1-3]. An acute fracture may also be seen with a direct blow to the spine as well as with neck hyperextension or forceful flexion, all of which can occur in various sports-related activities [1]. This fracture has been described in sports including football, soccer, golf, baseball, wrestling, power-lifting, trail-running, and horse-riding [1-7]. It is especially rare in children and adolescents, with only a few documented cases in the literature [3]
Treatment for clay shoveler's fracture is typically conservative with rest from painful activity, and most patients recover with a period of relative rest $[2,8]$. Occasionally, cases of delayed union or non-union fractures can cause ongoing symptoms. In such cases, options are limited, with some reported cases of surgical excision of the fracture fragment after 10 months of painful symptoms [8].

To our knowledge, this is the first case of an ultrasound-guided injection being used to treat this condition, facilitating symptom relief and a relatively rapid return to sport. While in this case the injection provided definitive symptomatic resolution, such an injection may also be useful to confirm pain related to a spinous process delayed union or non-union fracture prior to surgical excision.

\section{Disclosures/Conflicts of Interest}

None.

\section{Funding Source}

None.

\section{Acknowledgments}

None.

\section{References}

1. Posthuma de Boer J, van Wulfften Palthe AF, Stadhouder A, Bloemers FW (2016) The Clay Shoveler's Fracture: A Case Report and Review of the Literature. J Emerg Med 51: 292-297.

2. Kang DH, Lee SH (2009) Multiple spinous process fractures of the thoracic vertebrae (Clay-Shoveler's Fracture) in a beginning Golfer: a case report. Spine 34: 534-537.

3. Yamaguchi KT Jr, Myung KS, Alonso MA, Skaggs DL (2012) Clay-shoveler's fracture equivalent in children. Spine 37: 1672-1675.

4. Herrick RT (1981) Clay-shoveler's fracture in power-lifting. A case report. Am J Sports Med 9: 29-30.

5. Kim SY, Chung SK, Kim DY (2012) Multiple cervical spinous process fractures in a novice golf player. J Korean Neurosurg Soc 52: 570-573.

6. Koirala P, Wolpin S, Phuyal P, Basnyat B, Zafren K (2015) A Pain in the Neck. Clay shoveler's fracture due to cervical spine trauma. Wilderness Environ Med 26: 430-432.

7. Nuber GW, Schafer MF (1987) Clay shovelers' injuries. A report of two injuries sustained from football. Am J Sports Med 15: 182-183.

8. Murphy RF, Hedequist D (2015) Excision of symptomatic spinous process nonunion in adolescent athletes. Am J Orthop 44: 515-517.

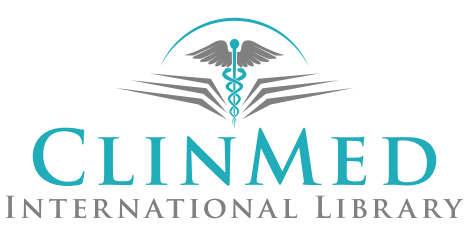

